\title{
BASES PARA EL ANÁlisis CONTRASTIVO DEL LÉXICO COLOQUIAL ESPAÑOL Y POLACO
}

\begin{abstract}
Resumen. En el presente texto planteamos diferentes elementos contrastables del léxico coloquial en español y polaco. Dichos elementos no constituyen un listado exhaustivo debido a la falta de espacio. No obstante, consideramos que son una base de partida para profundizar en la descripción del registro coloquial en español y polaco, y sobre todo, para analizar las dificultades que puedan tener los aprendices de español como lengua extranjera. También presentamos los conceptos de reconocimiento y percepción como herramientas para la descripción y el análisis contrastivo de dichos elementos.
\end{abstract}

Palabras clave: registro, español coloquial, informal, variedad lingüística.

\section{Introducción}

En la enseñanza y el aprendizaje de una lengua extranjera en un contexto educativo se suele hacer hincapié en aspectos gramaticales formales, que en el caso del español suelen ser aspectos como el uso correcto de los tiempos y modos verbales, el uso correcto de los artículos, la diferenciación entre los verbos ser y estar, etc. En los niveles iniciales la elección del léxico se basa en que sea neutro y pueda utilizarse en diferentes contextos y que, por lo tanto, sea recurrente. A medida que se avanza, se profundiza en el registro formal. Así, en el nivel C1 y C2 se posee un conocimiento mucho más amplio de vocabulario, conjunciones, marcadores, etc., y el aprendizaje se centra en contextos formales. Frente a ello, el conocimiento del registro coloquial queda relegado generalmente a la presentación puntual de cierto léxico, casi más como si de una curiosidad se tratara.

\footnotetext{
* Uniwersytet im. Adama Mickiewicza w Poznaniu.
} 
Así, la persona que se enfrenta a un idioma extranjero suele familiarizarse con el registro coloquial de manera directa, por contacto con nativos en un contexto real y sin la mediación de un profesor. Esto suele derivar en una percepción en ocasiones errónea, puesto que las fronteras de lo que se considera coloquial o formal en una $u$ otra lengua no tienen por qué ser idénticas. Por eso, el contacto entre un hablante nativo y un hablante no nativo puede derivar en la creación de falsas imágenes derivadas de un uso incorrecto de aspectos propios de los registros.

Cabe añadir que cuando nos referimos a los registros, no señalamos únicamente aspectos estrictamente gramaticales. La distancia que se mantiene entre los interlocutores, el tono, la comunicación no verbal, la organización del discurso, etc., también son muestras tanto de diferencias culturales como en ocasiones de registro.

Por lo tanto, la imagen errónea que en ocasiones podamos construirnos de una persona a través de la lengua que utiliza como interlocutor puede estar motivada por el desconocimiento de las características de los registros formal y coloquial en una lengua extranjera, y no necesariamente por la falta de cortesía o buenos modales.

\section{Reconocimiento y percepción del registro coloquial ${ }^{1}$}

Existen dos conceptos que derivan de esta aproximación del registro coloquial por parte de un alumno de lengua extranjera y que funcionan como herramientas a la hora de analizar el uso que hace de los registros. El primero de ellos es el del reconocimiento, entendido como la capacidad de discernir si una determinada característica de la lengua pertenece al registro coloquial o al registro formal. El segundo concepto es el de la percepción, entendida como la capacidad de comprender el uso que se hace de dicha característica de la lengua.

El reconocimiento y la percepción son dos conceptos que permiten estudiar y contrastar el uso que de determinadas propiedades hacen los usuarios de una lengua. Por ejemplo, las locuciones verbales "agachar el lomo" (s.f., s.v. lomo) y "romperse alguien los cuernos" (s.f., s.v. cuerno) son sinónimas y la RAE las presenta como coloquiales. Un usuario de la lengua las reconoce como coloquiales, pero no les otorga necesariamente un mismo grado de coloquialidad. Es decir, si un usuario colocara

\footnotetext{
1 A causa de las limitaciones de espacio, nos centraremos en presentar los conceptos de reconocimiento y percepción como herramientas de trabajo. En próximas publicaciones se ejemplificará su funcionamiento.
} 
estas dos locuciones verbales en un eje imaginario que representara el continuum de la lengua que va desde el registro coloquial hasta el registro formal, no lo haría en el mismo punto. Obsérvese la siguiente figura:

Registro formal Registro coloquial

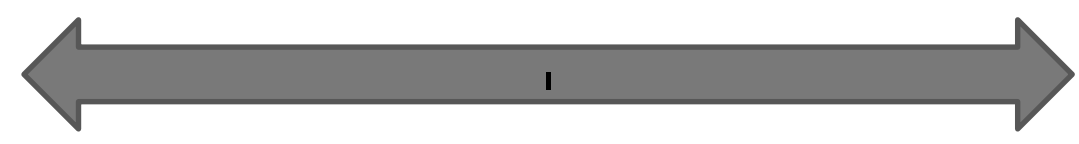

Fig. 1. Eje de los registros coloquial y formal

Fuente: elaboración propia.

Probablemente, el usuario, el cual posee la capacidad del reconocimiento, colocaría ambas colocaciones verbales a la derecha, en el espacio correspondiente al registro coloquial. No obstante, debido a la capacidad de la percepción, situaría "romperse los cuernos" más próximo al extremo del registro coloquial que "agachar el lomo", el cual sería colocado más cerca de la parte central. Incluso se podría dar el caso de que un usuario la colocara en el espacio del registro formal, dándose de esta manera un problema de reconocimiento.

Desde un punto de vista contrastivo es mucho más preciso analizar resultados de producciones teniendo en cuenta el reconocimiento y la percepción que los hablantes nativos tienen de diferentes aspectos de su lengua. Recurrir únicamente a la comprobación en un diccionario de referencia sobre si determinada palabra es descrita como coloquial o no, no tiene en cuenta la percepción real que un hablante tiene de dicha palabra. Además, los resultados obtenidos de dicho contraste serían cuestionables, puesto que se basarían en hipótesis planteadas a priori y no respecto a producciones reales de usuarios de la lengua.

En el caso de los aprendices de lenguas extranjeras el eje de los registros de su lengua materna se solapa con el eje de los registros de la lengua segunda, dando pie a que se den situaciones de incomprensión y se creen falsas imágenes entre los interlocutores, como señalábamos arriba. De ahí que cuando se plantee un análisis contrastivo de elementos característicos del registro coloquial sería conveniente considerar diferentes grupos de sujetos investigados y no solamente dos grupos de sujetos con lenguas maternas diferentes. 


\section{Elementos contrastables del léxico coloquial español y polaco}

En el presente apartado planteamos diferentes elementos contrastables del léxico coloquial en español y polaco. Dichos elementos, como se podrá suponer debido a las limitaciones del espacio disponible, no suponen un listado exhaustivo de todo aquello que se pueda contrastar entre dos lenguas ${ }^{2}$. No obstante, consideramos que son una base de partida para profundizar en la descripción del registro coloquial en español y polaco, y sobre todo, para analizar las dificultades que puedan tener los aprendices de español como lengua extranjera.

Existe la falsa creencia de que el léxico del registro coloquial es muy pobre en comparación con el del registro formal, idea que se ha visto reforzada a raíz del auge de la comunicación en redes sociales. Nada más lejos de la realidad. El léxico del registro coloquial puede ser aparentemente más limitado o muy variado y original. Todo ello depende de dos aspectos básicos: por una parte, la inmediatez de la conversación favorece la simpleza léxica, pero por otra, la carencia de encorsetamientos formales permite la creación de palabras para expresar nuevos conceptos sin imposiciones académicas. Así, en el apartado dedicado a las estrategias conversacionales se podrá comprobar cómo en ocasiones la pobreza o riqueza léxica son un elemento derivado de las necesidades de los interlocutores para atenuar o intensificar el mensaje.

\subsection{Palabras comodín}

Las palabras comodines, también llamadas pro-forma o palabras ómnibus, son aquellas que, por su significado difuso, sustituyen polisémicamente a amplios grupos de palabras. Las diferentes categorías que forman estas palabras suelen ser denominadas como pro-verbo, prosustantivo, pro-adjetivo y pro-adverbio. Gaviño Rodríguez (2008: 75) cita como ejemplos del español los pro-verbos hacer, tener, haber, poner, decir, echar o dar, los pro-sustantivos esto, algo, cosa o rollo, los pro-adjetivos estupendo, fuerte, guapo o guay, y el pro-adverbio así. Gómez Torrego (1995: 186-191) defiende que las pro-formas deberían ser de uso exclusivo en

${ }^{2}$ En Fernández Jódar (2015) presentamos otros aspectos del registro coloquial a tener en cuenta en una descripción. 
el registro coloquial y han de ser evitadas en el registro formal y en los textos escritos.

En polaco las palabras comodines referidas a verbos parecen ser menos frecuentes, aunque podemos encontrar ejemplos con los proverbos zrobić (esp. hacer) o mieć (esp. tener). También encontramos prosustantivos como to (esp. esto) o coś (esp. algo), pro-adjetivos como fajny (esp. estupendo) o pro-adverbios como tak (esp. así).

\subsection{Preferencias léxicas}

En el registro coloquial podemos encontrar ciertas preferencias léxicas de unos términos sobre otros, aunque estos se entiendan como sinónimos. En Gaviño Rodríguez (2008: 24) se señalan algunos ejemplos de cómo que se tiende al uso de dejar frente a permitir o de pero frente a sin embargo.

La mayor frecuencia de uso de unas palabras sobre otras también depende de la variante de la que se trate, como ocurre con la variación léxica en el mundo hispánico. Así, un término de uso frecuente en España como el verbo enfadarse, es reemplazado en países de América latina por el verbo enojarse.

También, la preferencia léxica ha llevado a que por ejemplo la palabra contable prenda haya caído casi en el olvido en favor de la incontable ropa.

En polaco Zdunkiewicz-Jedynak (2008: 46) presenta una situación similar con la conjunción bo (esp. porque) frente a otras formas de expresar la causalidad.

\subsection{Redundancias léxicas}

La redundancia léxica consiste en la repetición o el uso innecesario de una palabra o idea. Un ejemplo de uso frecuente en el español peninsular sería bajar abajo. Curiosamente, dado que la inmediatez de la comunicación exige de la economía de tiempo, parecería lógico pensar que en el registro coloquial no se deberían dar redundancias léxicas. No obstante, sucede todo lo contrario. Esto es debido a que las redundancias léxicas no deben ser entendidas como una muestra de mayor o menor conocimiento de la lengua, sino como elementos que refuerzan el mensaje o aumentan la expresividad. 
Ciertamente, pueden darse a causa de la falta de planificación del discurso. Aun así, también es frecuente encontrarlas en el registro formal. Gómez Torrego (1995: 199-201) señala redundancias léxicas que se pueden encontrar en el registro formal como conclusión final o periodo de tiempo, o en el registro coloquial como bajar abajo, entrar dentro o personas humanas.

En polaco existen ejemplos como cofnać się do tyłu (esp. retroceder hacia atrás), wracać z powrotem (esp. regresar de vuelta), wzajemna wspótpraca (esp. cooperar en común), spaść w dót (esp. caer abajo).

\subsection{Creaciones léxicas}

Otro aspecto que contradice la tradicional visión del registro coloquial como un registro limitado es la gran cantidad de mecanismos de creación léxica, alguno de ellos motivado por la economía del lenguaje, pero otros muchos son fenómenos que enriquecen el léxico. Muchos de estos mecanismos de creación léxica son comunes en el registro coloquial y en el formal, tanto en español como en polaco (Sorbet, 2017).

Algunos de estos recursos de creación léxica son:

- Sufijación. En español coloquial son muy productivos (Gómez Torrego, 2001: 47-50) el sufijo deverbal -e (corte, cante, acojone, descojone, desmadre), los sufijos -ata, -ota, -eta, -eto y -aca (bocata, pasota, fumeta, bareto, obreraca), el sufijo-eo (peloteo, magreo), el sufijo -da (cantada, parida), el sufijo -oso (cantoso), el sufijo -ero (motero, pastillero), entre otros.

En polaco coloquial los sufijos también son numerosos. Según Zdunkiewicz-Jedynak (2008: 102-103), los más productivos son -ara (szczęściara), -owicz (gapowicz), -anka (przepychanka), -ak (sztywniak), -ówa (kranówa), -uch (komuch), -us (ochlapus). También existen los sufijos -ec $\mathrm{y}-\mathrm{ol}$, despectivos hacia otras nacionalidades (angol, japoniec). Finalmente, cabe mencionar los sufijos aumentativos como -isko / -ysko (bucisko) y dinimutivos como -utki, -uśki, -eńki (cichutki). Como en el caso del español coloquial, esta es una lista inconclusa.

- Prefijación. En español coloquial se puede recurrir a prefijos para enfatizar como super- o re / requete- (supertarde, requetelisto).

En polaco coloquial tenemos prefijos como przy-(przykrótki, przymaty).

- Acortamiento. Aunque podemos caer en la tentación de considerar que el único motivo de los acortamientos léxicos es la economía y la inmediatez del discurso, debemos recordar que también se caracterizan por denotar familiaridad entre los interlocutores (Casado, 1985: 85). 
En español coloquial encontramos ejemplos como boli por bolígrafo, facu / facul por facultad, finde por fin de semana, uni por universidad.

En polaco coloquial existen ejemplos como matma (de matematyka, esp. matemáticas), fiza (de fizyka, esp. física), nara (de na razie, esp. hasta luego), info (de informacje, esp. información).

- Neologismos. La casi totalidad de neologismos recientes son anglicismos que han llegado a través de la cultura de masas y los medios de comunicación e Internet. Entre ellos tenemos, por ejemplo, cómo se denomina a los usuarios de diferentes redes sociales: youtuber, instagrammer, iger o muser. La universalidad de la cultura de masas ha conllevado que muchos de estos anglicismos aparezcan en español y en polaco. No obstante, en polaco encontramos neologismos del español que suelen ser utilizados en prensa deportiva gracias a la importancia del fútbol español. Así, el uso de cojones hace referencia a jugar con ímpetu y su uso no se entiende como vulgar.

- Alteración del significado. Por último nos gustaría mencionar en este apartado la alteración del significado estándar de una palabra mediante metáforas y metonimias. Así, por ejemplo, en la jerga de las drogas en español encontramos piedra, chocolate o chute. Otros ejemplos serían mal de la olla, empanada mental o sobre en referencia a la cama. En polaco dostać po ryju (esp. golpear en la cara, partir el morro), strzelić gola (esp. marcar un gol, chutar a gol).

Finalmente, debemos hacer hincapié en que estos recursos de creación léxica suelen ser mucho más productivos en el registro coloquial.

\subsection{El léxico del insulto}

El conjunto de palabras que forma el léxico del insulto es muy amplio. A grandes rasgos puede hacer referencia a baja capacidad intelectual, a rasgos físicos (fealdad, delgadez, gordura, altura, defectos físicos, etc.), sexo, lo escatológico, el comportamiento, las profesiones o la locura. Sin embargo, el léxico del insulto no es importante únicamente por su amplia presencia en el registro coloquial, sino también porque añade valores pragmáticos al discurso. Es, por tanto, una herramienta que puede acentuar la intención afectiva, de admiración o de asombro, puede marcar una relación de proximidad o intensificar el discurso.

Contrastar el léxico del insulto implica el tener en cuenta todos estos factores pragmáticos, ya que una determinada palabra vulgar no tiene por qué tener en dos idiomas dichos factores. Así, por ejemplo, el uso en 
español del vulgarismo coño como interjección para expresar diferentes estados de ánimo tendría su equivalente pragmático en el polaco kurwa, aunque semánticamente tengan diferentes significados.

El léxico del insulto es un elemento del que estamos seguros de que el reconocimiento y la percepción como herramientas para entender su funcionamiento en diferentes lenguas podrían tener un papel clarificador.

\section{Conclusiones}

En el presente artículo hemos presentado ciertos aspectos del léxico coloquial que podrían ser tenidos en cuenta a la hora de contrastar sus usos tanto en polaco como en español y en el uso que los estudiantes de lenguas extranjeras hacen de ellos.

Para analizarlos proponemos el uso de los conceptos de reconocimiento y percepción, los cuales pueden mostrar con mayor precisión el uso que se hace de los aspectos anteriormente referidos. Evidentemente, deben aplicarse a la hora de analizar los resultados de estudios realizados sobre producciones de hablantes nativos y aprendices de lenguas extranjeras.

Por otra parte, aunque en el presente trabajo hemos hecho hincapié en el léxico coloquial, debemos recordar que se debería realizar también un análisis contrastivo de otros aspectos del registro coloquial como la sintaxis o las estrategias conversacionales.

\section{Bibliografía}

ANUSIEWICZ, J. (1992). «Potoczność jako sposob doświadczania świata i jako postawa wobec świata», en J. ANUSIEWICZ y F. NIECKULA (eds.), Jezzyk a kultura, t. 5: Potoczność w jezyku i w kulturze. Wrocław: Wydawnictwo Uniwersytetu Wrocławskiego, 9-20.

BARTMIŃSKI, J. (1991). «Styl potoczny jako centrum systemu stylowego języka», Poradnik Jezykowy, 10-23.

BRIZ GÓMEZ, A. (coord.) (1995). La conversación coloquial. Materiales para su estudio. València: Universitat de València.

BRIZ GÓMEZ, A. (1996). El español coloquial. Situación y uso. Madrid: Arco Libros. BRIZ GÓMEZ, A., Grupo Val.Es.Co. (2002). Corpus de conversaciones coloquiales. Madrid: Arco Libros.

CASADO, M. (1985). Tendencias en el léxico español actual. Madrid: Coloquio. 
FERNÁNDEZ JÓDAR, R. (2015). «El español coloquial en la clase de E / LE en contexto académico. Teoría y práctica», en E. STALA, R.S. BALCHES ARENAS y C. TATOJ (eds.), Tendencias en la enseñanza de español LE. Perspectivas glotodidácticas y metodológicas contemporáneas (monografía). Cracovia: Księgarnia Akademicka, 277-296.

GAVIÑO RODRÍGUEZ, V. (2008). Español coloquial. Pragmática de lo cotidiano. Cádiz: Servicio de publicaciones de la Universidad de Cádiz.

GÓMEZ TORREGO, L. (1995). El léxico en el español actual: uso y norma. Madrid: Arco Libros.

GÓMEZ TORREGO, L. (2001). «El lenguaje actual de los jóvenes», Carabela. Modelos de uso de la lengua española. Madrid: SGEL, 39-60.

HOŁOWKA, T. (1986). Myślenie potoczne. Heterogeniczność zdrowego rozsądku. Varsovia: Państwowy Instytut Wydawniczy.

JANKOWSKA, K. (2014). «Algunas características léxicas del español coloquial», en R. FERNÁNDEZ JÓDAR et al. (eds.), Lingüística española en Polonia: líneas de investigación. Poznań: Wydawnictwo Naukowe Uniwersytetu im. Adama Mickiewicza, 75-82.

LÓPEZ SERENA, A. (2007). «El concepto de 'español coloquial': vacilación terminológica e indefinición del objeto de estudio», Oralia, 10, 161-191.

NOWIKOW, W. (2006). «Sobre algunos conceptos básicos de la lingüística etológica», en M. SCHRADER-KNIFFKI (ed.), La cortesía en el mundo hispánico. Nuevos contextos, nuevos enfoques metodológicos. Madrid / Frankfurt am Main: Iberoamericana / Vervuert, 183-190.

POLAŃSKI, K. (ed.) (1999). Encyklopedia językoznawstwa ogólnego. Wrocław: Ossolineum.

REAL ACADEMIA ESPAÑOLA (s.f.). Diccionario de la lengua española [en línea] $<$ http://www.rae.es>, fecha de consulta: 10 de febrero de 2018.

SCHRADER-KNIFFKI, M. (ed.) (2006). La cortesía en el mundo hispánico. Nuevos contextos, nuevos enfoques metodológicos. Madrid / Frankfurt am Main: Iberoamericana / Vervuert.

SORBET, P. (2017). «Los mecanismos de creación léxica en español y polaco», Studia Romanistica, 17 (1), 129-140.

ZDUNKIEWICZ-JEDYNAK, D. (2008). Wykłady ze stylistyki. Varsovia: PWN. 